\title{
BOURDIEU, SAYAD E A DESCOBERTA DO TRABALHO: DA ECONOMIA TRADICIONAL À ECONOMIA CAPITALISTA
}

\section{BOURDIEU, SAYAD AND LABOUR'S DISCOVERY: FROM TRA- DITIONAL ECONOMY TO CAPITALIST ECONOMY}

\author{
Leandro Augusto dos Remédios Costa* \\ Juarez Lopes de Carvalho Filho**
}

BOURDIEU, Pierre; SAYAD, Abdelmalek. El desarraigo: La violencia del capitalismo en una sociedad rural. Traducción: Ángel Abad y Luciano Padilla López. - 1a ed. - Buenos Aires: Siglo Veintiuno Editores, 2017. 272 p.

O livro El desarraigo: la violencia del capitalismo en una sociedad rural, de Pierre Bourdieu e Abdelmalek Sayad, lançado em 2017 em espanhol, pela Editora argentina Siglo Veintiuno Editores, foi publicado originalmente em 1964, com o título Le déracinement: la crise de l'agriculture traditionnelle en Algérie. Trata-se da reprodução da edição de 1965, da editora Nova Terra, de Barcelona, com o título A Argélia entra en la historia, que encontrava-se esgotada. Destaca-se que a atual edição foi coordenada por Amín Perez, sociólogo da Republica Dominicana, doutor em sociologia pela École des Hautes Études en Sciences Sociales, que além de um Prefácio "La liberación del conocimiento: Bourdieu y Sayad frente al colonialismo" ${ }^{1}$, revisa e acrescenta alguns apêndices ausentes na primeira edição.

El desarraigo faz parte de um conjunto de pesquisas realizadas por Bourdieu, em

\footnotetext{
* Professor da Faculdade Santa Terezinha - CEST - (São Luís/MA/Brasil). Doutorando em Ciências Sociais pela UFMA. E-mail: leandroaugustocosta7@gmail.com

** Professor do Programa de Pós-Graduação em Ciências Sociais da Universidade Federal do Maranhão UFMA - (São Luís/MA/Brasil). Doutor em Ciências Sociais e Econômicas pelo Institut Catholique de Paris. E-mail: juarez.lopes@gmail.com

1. Este prefácio coloca em perspectiva a história que constitui a originalidade deste livro. Diferente dos outros estudos que buscam fazer uma exegese da obra de Bourdieu sobre a Argélia baseados no contexto
} 
colaboração com outros pesquisadores que buscam compreender os impactos do capitalismo moderno na sociedade campesina, no contexto da guerra de Independência da Argélia. Podemos citar as principais publicações: Sociologie de l'Algérie (de 1958); Travail et travailleurs en Algérie (1963), escrito em conjunto com Alain Darbel e Jean-Paul Rivet.

Após seus estudos de filosofia na École Normale Superieure, em Paris, e breve passagem pelo liceu em Moulins, Bourdieu, como vários jovens da sua idade àquela época, é enviado contra a vontade para a Argélia, em 1955, para prestar seu serviço militar, período em que se intensifica a guerra de Independência deste país com a França (1954-1962). Primeiro, Bourdieu estará vinculado ao regime de infantaria encarregado de proteger as bases aéreas e outros sítios estratégicos na região Chélif (150 $\mathrm{km}$ a oeste de Argel). Contudo, graças ao coronel Durcourneau, originário do Béarn, terra natal de Bourdieu, e parente de sua mãe, ele obtém transferência para o serviço de documentação e de informação do Gouvernement général, em Argel. Ali, conhece vários pesquisadores, como por exemplo, o historiador André Nouschi, e aproveita o material da biblioteca de maior acervo do Gouvernement général para ler a literatura etnológica colonial sobre a Argélia e se aprofundar em autores como Marx, Weber, Durkheim, Margaret Mead e Lévi-Strauss. Disto resulta seu primeiro livro Sociologie de l'Algérie, que representa uma verdadeira iniciação à sociologia. É bom lembrar que Bourdieu havia se engajado numa tese de filosofia sobre a Structure temporelle sur la vie affective, sob a direção de Georges Canguilhem (MARTIN-CRIADO, 2008, p. 2931; 2012, p. 77-78; YACINE, 2008, p. 13).

Em 1957, após seu serviço militar, Bourdieu torna-se assistente na Faculdade de Letras da Universidade de Argel, para lecionar filosofia e sociologia (autores como Kant, Durkheim, Saussure, Lévi-Strauss), local onde encontra e tem como aluno Abdelmalek Sayad ${ }^{2}$. Ainda na Argélia, Bourdieu estabelece relações com a Association pour la Recherche Démographique, Économique et Sociale (ARDES), associação contratada pelo exército francês para fazer um estudo sobre as populações que foram deslocadas durante a guerra para campos de reagrupamento. Bourdieu é convidado para coordenar a pesquisa e fazer interpretação sociológica dos dados estatísticos. É a primeira pesquisa empírica e a primeira vez que ele endossa o papel de pesquisador organizando a pesquisa de campo e recrutando pesquisadores e estudantes, entre eles Sayad (MARTÍN-CRIADO, 2008, p. 52). A pesquisa, que se desenvolverá em quase toda a Argélia, é redefınida,

da guerra de Independência, Amín Perez se baseia em análises feitas dos arquivos pessoais de Bourdieu e Sayad, cujo investimento resultou numa tese de doutorado "Rendre le social plus politique: guerre coloniale, immigration et pratiques sociologiques d'Abdelmalek Sayad et Pierre Bourdieu”, EHESS, 2015, publicada pela Agone com o título "Faire de la politique avec la sociologie" (2019).

2. Como afirma Perez (2017), os debates promovidos por Bourdieu sobre a atualidade colonial cria de imediato entre os dois afinidades intelectuais e afetivas. Isso tem muito a ver com a similaridade de suas trajetórias. Ambos vêm de meios sociais modestos e cursam escolaridades de excelência. Bourdieu, filho de camponês, se tornou funcionário dos correios, e transitou pelas instituições acadêmicas de maior prestígio na França. E Sayad, descendente de uma pequena elite rural em decadência, seu pai logrou escolarizá-lo em instituições de ensino destinadas a europeus. Os dois sofreram profundamente com as discriminações por suas origens sociais (PEREZ, 2017, p. 9). 
centrando-se em diferentes aspectos: sobre a habitação e emprego, a destruição e a miséria da sociedade argelina, causadas pela colonização e a guerra, e sobre a passagem de uma sociedade pré-capitalista à sociedade capitalista. Podemos afirmar que a Argélia exerce um papel fundamental na formação da sociologia de Pierre Bourdieu. É neste contexto que ele inicia sua passagem da filosofia à sociologia, passando pela antropologia econômica. E, desse modo, em $E l$ desarraigo, como atesta Amín Perez, o ponto de partida são os estudos das políticas coloniais de expropriação de terra, os efeitos dos deslocamentos e reagrupamentos forçados de trabalhadores rurais e campesinos, para evitar seus contatos com os "rebeldes" independentes, assim como o impacto do capitalismo ou sua economia baseada sobre a reciprocidade e a solidariedade $(2017$, p. 8).

0 desvelamento da situação social argelina no contexto de guerra representa o combate de Bourdieu e Sayad contra as atrocidades da guerra. Nos anos 1960, a situação é explosiva e a violência de extrema direita contra os Mulçumanos e Franceses de esquerda se exacerbam com os rumores de golpe de Estado militar. Bourdieu é informado de que as associações de extrema direita o inseriram em sua "lista vermelha", o que implicava grande perigo. Diante disso Bourdieu volta a Paris. Raymond Aron lhe propõe um posto como seu assistente na Sorbonne. Ele passa um ano na Sorbonne, em seguida vai para a universidade de Lille, onde ensina dois anos ao mesmo tempo em que está vinculado como secretário do Centre de sociologie européenne, presidido por Aron. Em 1964, é nomeado diretor de estudos à EHESS. Nesse período ele analisa os materiais da pesquisa, que resultam nos livros Travail et travailleurs en Algérie, centrado nos trabalhos urbanos, subprole- tários, operários, artistas (1963) e Le déracinement (1964).

Segundo Martín-Criado, Le déracinement (El desarraigo) além de uma formidável denúncia dos deslocamentos massivos, das destruições dos vilarejos pelo exército francês e a exploração de terras pelo poder colonial, a obra é uma análise penetrante das transformações engendradas nas sociedades campesinas por esses fatores e, por extensão, das relações capitalistas. Nessa perspectiva, Bourdieu utiliza dois elementos principais: os tipos-ideais, desenvolvidos por Max Weber, e uma teoria das disposições, do ethos, onde já se encontra alguns traços daquilo que será a teoria do habitus.

El desarraigo está dividido em oito capítulos, contendo ainda uma introdução e quatro Apêndices que são documentos que trazem dados empíricos quantitativos, cartografias, dos reagrupamentos das populações e os aspectos da "descampesinización".

A Introdução do livro contextualiza o reagrupamento da população, afirmando que se trata do deslocamento da população rural argelina entre 1955 e 1962 e que tinha como objetivo subtrair a população da influência rebelde, sobretudo da ANL (Exército de Libertação Nacional). Em 1960, o número de Argelinos reagrupados atinge mais de 2,15 milhões, aproximadamente um quarto da população total. Levando-se em conta o êxodo para as cidades, a estimativa era de 3 milhões, ou seja, a metade da população rural. Esse deslocamento, segundo os autores, está entre os mais brutais da história (p. 29).

No primeiro capítulo "Los reagrupamientos de población y la lógica del colonialismo", os autores tratam da política agrária via leis agrárias, mostrando que estas tinham como objetivo criar condições para desenvolver uma economia moderna, 
fundada na empresa privada e na propriedade individual por meio da destruição das bases econômicas da integração das unidades tradicionais de resistência. Para isso os autores se apropriaram, além das leis agrárias, dos censos agrícolas (de 1950-1951) e outras estatísticas. Os camponeses perdem propriedades territoriais, passam por uma proletarização e abandonam numerosas tradições agrícolas. Nesse contexto o tradicionalismo ancestral é substituído por um tradicionalismo da desesperança (ligado a uma economia de sobrevivência) ou a migração forçada às cidades ou a França. Os autores mostram que os reagrupamentos aceleram de forma direta e indireta (êxodo rural e ruptura com rotinas tradicionais, respectivamente) o processo de abandono de ocupações agrícolas. Os objetivos da política colonial oscilam entre pólos opostos: desintegrar (para integrar) ou integrar (para desintegrar). Dessa forma, concluem que o colonialismo se apoia numa ideologia integracionista onde o conservadorismo segregacionista, que invoca as diferenças de fato para negar a igualdade jurídica, só se opõe em aparência ao assimilacionismo, que nega as diferenças de fato em nome da identidade de direito.

No segundo capitulo, "Dos historias, dos sociedades”, Bourdieu e Sayad introduzem o conceito de culturización e desculturización, que implica na ação da potência orientada para destruir os fundamentos econômicos da ordem social tradicional determinando a "perda" de valores e formas próprias sem compensação. Além disso, esta noção está ligada a um tradicionalismo da desesperança, imposto pelo desaparecimento de garantias e defesas que proporcionavam uma sociedade integrada. A aculturação, afirmam, nunca é resultado de um simples contado de civilizações, só se se esconde o contexto no qual se realizam as mudanças: a situação colonial. 0 efeito específico do intervencionismo colonial é a aceleração patológica da mudança cultural e sua característica é uma contradição insuperável: ignorar a lógica da sociedade sobre a qual atua o colonialismo. Neste capítulo os autores descrevem e analisam duas regiões da Argélia que são escolhidas como casos exemplares: 0 Maciço de Colo e 0 Vale de Chélif, para mostrar, por meio de diferenças ideais-típicas construídas entre elas, as diferenças internas no processo de colonização.

Em "Los reagrupamientos y la crisis de la agricultura tradicional”, terceiro capítulo, os autores selecionam três reagrupamentos diferentes: de Kerkera, de Ain-Aghbel e de Djebabra. Eles concluem que os obstáculos objetivos ligados aos reagrupamentos não bastam por si só para justificar o abandono das atividades agrícolas e concluem postulando que essas diferenças sugerem a necessidade de precisar os limites e determinar a ação específica do desenraizamento (os autores se apoiam na fala dos camponeses, em dados estatísticos e informações históricas).

O capítulo quatro analisa, "El descubrimiento del trabajo”. A renúncia à agricultura está ligada não somente a obstáculos objetivos, mas às mudanças de atitude em toda existência campesina. Analisam os índices de ocupações (por meio das categorias socioprofıssionais divididas por regiões e por reagrupamentos) dos diferentes grupos para compreender as atividades efetivas e a atitude com relação ao trabalho. Segundo eles, o que varia é a maneira particular de viver e expressar a crise. Fundamentam-se nas declarações dos indivíduos para mostrar que duas pessoas com ocupações idênticas podem considerar ou não como autêntico o trabalho. Os autores citam sete 
reagrupados, suas concepções de trabalho e intenções, mostrando que entre os reagrupados de Ain-Aghbel e Kerkera alguns se negam a considerar como trabalho as tarefas que não proporcionam trabalho permanente e outros, ligados a terra e a agricultura, continuam considerando estas sua única atividade possivel.

No quinto capítulo "Thafallah'th o el campesino realizado", Bourdieu e Sayad afirmam que para entender os abalos do reagrupamento é preciso recordar o sistema de valores inseparável da condição campesina tradicional. Para isso analisam os ditos e provérbios dos idosos e citam longos relatos de dois senhores. Disto decorre que ser campesino é realizar um conjunto de modelos que constituem a cultura campesina. Todas as virtudes campesinas se resumem na palavra niya, que significa simplicidade, retidão, inocência, etc. Bu-niya, o homem campesino, ignora o cálculo, tanto no sentido contável quanto especulativo quanto ao futuro, pois não pretende torcer os desígnios divinos. Os autores identificam a estrutura oposicional do sistema de valores: a "estupidez" dos depositários da tradição se a opõe a "inteligência” ou inovação dos mais jovens, enquanto os mais velhos denunciam sua diabólica malícia. Progressivamente as relações mercantis substituem as que obedecem as lógicas da honra, caem em desuso as tradições e sentimentos comunitários e se desenvolve o individualismo. Numa sociedade rural que considera a agricultura como uma atividade menor, são as mulheres que atuam como últimas defensoras do thafellah'th (a condição camponesa). A descampesinização não é a negativa de realizar tarefas agrícolas, estas seguem se desenvolvendo, mas uma forma contrária ao espírito tradicional em nome de uma atitude de "cálculo".
No capítulo que segue, o sexto, "Una agricultura sin agricultores" os autores analisam os reagrupamentos de Matmata e Djebabra; nestes, apesar da pauperização os fellah'in del Chelif despossuídos de suas terras continuam se declarando camponeses. 0 espírito camponês pode se perpetuar sendo estranho, indiferente e hostil a outros tipos de vida, mesmo que tenha que enfrentar a vida urbana. Estes camponeses põem seus cinco sentidos para passar pelo reagrupamento sem negar sua qualidade de camponeses. Por outro lado, em outras regiões várias são as influências que têm minado a atitude camponesa tradicional frente ao mundo: a escolarização, o trabalho assalariado, a generalização das trocas monetárias e a difusão do espírito econômico. 0 reagrupamento gera a descampesinização, ou seja, a tomada de consciência da renúncia íntima dos valores tradicionais, da qual serve como índice tanto a declaração de estar parado como a proliferação de comércios. Os autores encerram este capítulo afirmando que há resistência às manipulações arbitrárias, mais nos reagrupamentos de Collo do que em Chelif. A rebeldia, dizem, é um índice de integração, mas também uma força de integração que une os indivíduos na repulsa e na esperança. As resistências pacíficas se manifestam na renúncia à agricultura e no contato contínuo com o Exército de Libertação Nacional (ANL).

No sétimo capítulo, "Ciudadanos sin ciudad”, Bourdieu e Sayad constatam que a ruína das bases morfológicas altera a realidade social em todos os níveis, incluindo a significação dos comportamentos, devido à interdependência que relaciona a estrutura da organização do espaço a dos grupos e ao tipo de sociabilidade. A ação das autoridades visa "fazer evoluir" na população argelina as 
estruturas e atitudes sociais de tipo ocidental. Os laços tradicionais tendem a se debilitar e solidariedades de outro tipo, baseadas na vizinhança e identidade das condições de existência, tendem a aparecer. 0 reagrupamento aproxima populações separadas por suas tradições culturais, favorece o confronto de condutas e opiniões. 0 crescimento do volume do grupo favorece a aparição de um tipo original de sociabilidade.

A aparição do véu feminino é um signo da transformação do estilo das relações sociais. No reagrupamento os espaços masculinos e femininos se interferem determinando a aparição do véu. Para os militares, a condição da mulher argelina era o signo mais manifesto da 'barbárie', por isso tentaram derrubar tudo que parecia um obstáculo a "liberação da mulher". Os autores afirmam que o estudo estatístico do consumo das famílias confirma os dados de observação direta. Os camponeses de Kerkera recorrem a três imagens para anunciar sua experiência: da nudez, da prisão e da escuridão noturna. Porém, o que expressa melhor a descampesinização é a "lenguaje del cuerpo, la manera de "tenerse", de llevar la cabeza o andar” (p. 188). Além disso, a relação com o tempo e valores também é uma expressão dessa descampesinização, tendo em vista que o camponês descobre a oposição entre o tempo "vazio" ou "perdido" e o tempo "cheio" ou ativo, próprio da lógica capitalista ${ }^{3}$.

No oitavo capítulo do livro, "Mezcolanza cultural", os autores sustentam que a situação colonial cria camponeses descam- penizados que se definem negativamente e que levam em sua existência todos os contrários. Nesse contexto, afirmam que é tentador selecionar um dos aspectos opostos de uma realidade contraditória, seja para concluir que o camponês está condenado ao arcaísmo ou que é portador de ideais revolucionários. Para os autores "Los modelos de comportamiento y el ethos econômico importados por la colonización, coexisten - en cada individuo - con los modelos y ethos heredados de una tradición ancestral..." (p. 201). Tomando como exemplo o trabalho, a atividade pode ser interpretada tanto pela lógica da honra quanto do interesse. A ambiguidade está no próprio objeto, a realidade é objetivamente contraditória. Os camponeses seguem fins contraditórios (perseguem fins tradicionais com meios modernos e vice-versa), é impossível a eles escolher entre as duas lógicas, portanto, buscam se beneficiar de ambas. Nas palavras dos autores, “... como no puede articular bien las dos lenguas culturales (para poder separarlas netamente), se condena a las interferencias y contradicciones que dan lugar a la actual mezcolanza cultural" (p. 205).

Mesmo com a abolição do sistema colonial e, portanto, das causas objetivas das contradições da conduta, não desaparecem todas as contradições. Nas palavras dos autores "El sistema colonial perdura en la medida en que las contradicciones que él ha dejado trás de sí no han sido efectivamente superadas...” (p. 207). As maneiras de agir e pensar, afirmam, podem sobreviver a uma

3. Tanto a questão da linguagem corporal quanto as atitudes em relação ao tempo foram retomadas em 1972, em Esquisse d'une théorie de la pratique, précedé par Trois études d'ethnologie Kabyle, e, depois, em Le Sens pratique (1970). Esquisse de la théorie de la pratique foi revisado e reeditado em 2000 por Bourdieu que o dedicou a Sayad. 
mudança de condições de existência, ou seja, "se puede liberar al campesino del colono y no liberarle de las contradicciones que la colonización desarrolló en él” (208). Os autores tecem críticas as ações contraditórias dos socialistas libertários e dos socialistas centralizadores que acabam por servir a si mesmos ao invés dos camponeses.

Como conclusão, Bourdieu e Sayad questionam em que medida uma política racional é compatível com as contradições que o camponês leva em si mesmo. Para os autores, a intervenção não pode se limitar ao campo econômico, "puesto que las opciones económicas son también, y esencialmente, opciones culturales” (p. 213). É por meio de uma ação educadora total, integral, que se pode superar as contradições. A ação educativa deve adaptar-se às atitudes e aspirações dos camponeses, ou seja, não "proponer de modo arbitrario exigencias definidas abstractamente por sujetos abstractos (p. 214)".

Como lembra Amín Perez em seu Prefácio, "estamos diante de uma obra revolucionária em termos científicos e profundamente política. El desarraigo renova a prática das ciências sociais e rompe com esquemas disciplinares que dividiam nossos comportamentos e representações entre etnologia do Terceiro Mundo e do Ocidente" (PEREZ, 2017, p. 20). Bourdieu e Sayad "erigem a sociologia como um aporte político da sociedade. Isso explica porque ambos continuarão trabalhando os processos de dominação na pós-colonialidade tanto no campo da educação e da cultura, como no campo da migração. Dois caminhos que se devem ao mesmo princípio: o conhecimento como meio de ação para mudar a realidade social” (PEREZ, 2017, p. 20).

A publicação espanhola de El desarraigo contribui para ampliar o acesso a uma parte da obra de Bourdieu pouco conhecida do público brasileiro ${ }^{4}$, notadamente da nova geração ${ }^{5}$ : os seus primeiros trabalhos sobre a sociedade argelina, cujas obras não são traduzidas em português. A obra será sem dúvida um instrumento de trabalho para aqueles, mas não só, engajados nos estudos sobre o campesinato e os impactos sofridos pelas transformações do capitalismo e o agronegócio no Brasil.

\section{Referências}

GARCIA JÙNIOR, A. Libres et assujettis: marché $\mathrm{du}$ travail et modes de domination au Nordeste. Paris, Éditions de la Maison des Sciences de l'homme 1989 .

LOPES, J. S. O vapor do diabo: o trabalho dos operários do açúcar. Rio de Janeiro: Paz e Terra, 1978.

MARTIÍN-CRIADO, E. Les deux Algéries de Pierre Bourdieu. Bellecombe-en-Bauges. Editions du Croquant: 2008.

MARTÍN-CRIADO. L'Algérie comme terrain d'apprentissage du jeune sociologue. In LEBARON, F.; MAUGER, G. Lectures de Bourdieu. Paris: Ellipses, 2012. PP. 77-93.

4. No Brasil, existe uma versão abreviada em português intitulada Desencantamento do mundo: estruturas econômicas e estruturais temporais. São Paulo: Perspectiva, 1979.

5. É importante lembrar que nos anos 1970 as pesquisas realizadas no Museu Nacional, no Rio de Janeiro, se apoiaram nesses trabalhos de Bourdieu para analisar as transformações do trabalho na economia do açúcar em espaços sociais rurais e urbanos. Podemos citar Lopes (1978) e Garcia Jr. (1989). Ver também a entrevista de Afrânio Garcia Jr. Publicada neste número da REPOCS. 
PEREZ, A. "La liberación del conocimiento: Bourdieu y Sayad frente al colonialismo". In: BOURDIEU, P.; SAYAD, A. El desarraigo: La violencia del capitalismo en una sociedad rural. Buenos Aires: Siglo Veintiuno Editores, 2017. PP. 7-20.

YACINE, T. Bourdieu et l'Algérie, Bourdieu en Algérie. In BOURDIEU, P. Esquisses algériennes. Paris: Seuil, 2008. PP. 11-20. 